\title{
COMPOSITORAS OLVIDADAS: UNA APROXIMACIÓN A LA OBRA DE REMEDIOS DE SELVA Y TORRE
}

\author{
Ana Blanco González \\ Universidad de La Rioja \\ anablancog@gmail.com
}

RESUMEN: Remedios de Selva y Torre fue una compositora sobre la cual se tenían pocos datos. La investigación parte de unas partituras encontradas en la Biblioteca Nacional de España, catorce composiciones en concreto. Posteriormente se han localizado tres más y se sabe de la existencia de otras cinco obras, de las que no se han localizado aún las partituras. Es probable que, conforme avance la investigación, pueda aparecer un número mayor de éstas.

Mediante la búsqueda de obras y documentos musicales, así como otros documentos que se trabajan en la presente investigación relacionados con Remedios de Selva, trataremos de clarificar su obra compositiva. Además, se contribuirá a hacer visible la dificultad de las mujeres para dedicarse a la composición y a ser valoradas en la esfera pública.

Palabras clave: mujeres compositoras, Remedios de Selva.

\section{FORGOTTEN WOMEN COMPOSERS: AN APPROACH TO THE WORK OF REMEDIOS DE SELVA Y TORRE}

\begin{abstract}
Remedios de Selva y Torre was a woman composer above which we had little bit information. The research was initiated from different scores that were found in the Spanish National Library, fourteen works concretely. Subsequently, three more scores have been located and it is known about the existence of five more, although the scores have not been founded yet. Likely, as the investigation advances, a mayor number of them may appear.
\end{abstract}


Throughout the search of works and musical documents as well as other documents that are being working in this present research related to Remedios de Selva, we will try to clarify her work. Besides it will contribute to make visible the women difficulty to work as a composer and be appreciated in the public eye.

Keywords: Women composers, Remedios de Selva.

Recibido: 29 de marzo de 2020

Aceptado: 10 de noviembre de 2020

\section{Biografía}

Remedios Teresa de Selva y Torre nace en Bilbao el 17 de octubre de $1877^{1}$. Su padre, Constantino Ramón Joaquín Victorio de Selva y López Osorio, de 23 años y natural de Villena (Alicante), estuvo ausente en su nacimiento. Capitán graduado, teniente agregado al Regimiento Infantería de África número siete, se encontraba de guarnición esa noche en Navarra. Constantino de $\mathrm{Selva}^{2}$ era hermanastro de Vicenta de Selva (nacida en Madrid), esposa del ilustre compositor Ruperto Chapí.

El padre de Vicenta y Constantino (abuelo de Remedios de Selva por la línea paterna), Narciso Buenaventura de Selva y Blanes ${ }^{3}$, nacido en Villena, fue abogado y diputado en las Cortes, residiendo así en Madrid. No llegó a conocer a su nieta ya que falleció antes de su nacimiento.

1. Partida de nacimiento conservada en el Archivo administrativo histórico del Conservatorio Superior de Madrid.

2. Constantino de Selva, comandante del Ejército, es destinado a Zona Madrid, 57 en 1894. Posteriormente, entre sus destinos figuran los siguientes: Regimiento de Reserva de Ciudad Real, 83 en 1897, La Coruña, 88 en 1901, Talavera de la Reina, 50 en 1902 y Regimiento de Burgos, 36 en 1904 (Anuario Militar de España 1897-1902). El 18 de enero 1906, el diario oficial La Correspondencia Militar anuncia su baja en el Ejército por fallecimiento. Previamente, en 1905, Constantino de Selva escribió una novela titulada El Grito de la Conciencia: "Según se nos dice, muy pronto se pondrá a la venta una novela titulada El Grito de la Conciencia, original del bizarro e ilustrado comandante del Regimiento de Burgos, D. Constantino Selva. También se nos asegura que dicha novela es altamente moral y una prueba evidente de la vastísima ilustración de su autor. Celebraremos mucho que la edición se agote inmediatamente"

"Noticias". Mensajero Leonés (12 de septiembre de 1905), p. 2.

Una vez publicada la novela, el mismo diario lo anuncia entre sus artículos: "El Grito de la Conciencia. Este es el título de una novela, muy bonita y eminentemente moral, que acaba de ponerse a la venta, al precio de 3 pesetas, en la librería del señor Miñón. Su autor, el comandante don Constantino Selva ha tenido la atención de regalarnos un ejemplar, elegantemente impreso en la citada imprenta. Cuando terminemos su lectura prometemos hablar más extensamente de este libro, que no dudamos en recomendar a nuestros lectores. A su autor enviamos nuestra enhorabuena"

"Noticias". Mensajero Leonés (22 de noviembre de 1905), p. 2.

3. Narciso Buenaventura Selva escribió Comentarios al código penal reformado y planteado provisionalmente por Ley de 3 de Junio de 1870. Previamente realizó la traducción al castellano en 1845 del Espíritu de las leyes (tomos I y II) de Montesquieu. 
De su madre, Doña Teresa Torre e Iturbe, solo sabemos que tenía 23 años cuando nació Remedios de Selva y que era natural de Bilbao. Los abuelos maternos de Remedios, Ramón Martín de Torre y Patricia de Iturbe, también eran naturales y residentes en Bilbao.

El 20 de septiembre de 1893 Remedios de Selva, con el consentimiento de su padre, solicita el ingreso en cuarto año de Piano y $1^{\circ}$ de Armonía en el Conservatorio Nacional de Música y Declamación en Madrid. Redacta una solicitud formal dirigida al recién nombrado director del centro, Ildefonso Jimeno de Lerma, manuscrita y firmada por la propia Remedios de Selva, que en ese momento estaba cerca de cumplir los 16 años.

Doña Remedios de Selva y Torre, hija de Don Constantino Selva y Osorio y Doña Teresa Torre é Iturbe, natural de Bilbao, provincia de Vizcaya, y de quince años de edad; a V.E. expone que deseando ingresar en el Conservatorios Nacional de Música para perfeccionar sus estudios de piano y cursar los de Armonía y Composición, es por lo que, y acompañando la correspondiente partida de bautismo de la interesada, a V.E. suplica de las órdenes convenientes para que la recurrente sea admitida a examen de ingreso con conocimiento de piano y de Solfeo, a fin de que le sea expedida la oportuna matrícula para continuar sus referidos estudios de piano y Armonía en el próximo curso académico, gracia que no duda alcanzar de V.E. cuya vida guarde Dios muchos años.

Madrid 20 de septiembre de 1893

Los exámenes de ingreso al Conservatorio se realizaban de forma diferente dependiendo de si los aspirantes poseían o no conocimientos musicales. Además, los diferentes reglamentos que se sucedieron marcaban los límites de edad mínimos y máximos para el acceso a los estudios musicales. Estos podían variar en función de las diferentes enseñanzas instrumentales o teóricas.

La enseñanza musical privada servía a los alumnos como ayuda, ya que preparaban las pruebas de acceso al Conservatorio en academias o clases particulares. En ocasiones, los mismos profesores del Conservatorio atendían en sus casas a los futuros aspirantes, lo cual producía desigualdad de oportunidades entre dichos candidatos a la hora de participar en el proceso selectivo.

De la solicitud para la realización de las pruebas de ingreso al Conservatorio, podemos inferir que Remedios de Selva se propuso el acceso a un nivel avanzado. Para ello tuvo que demostrar los conocimientos teóricos y prácticos requeridos. Finalmente fue admitida en el curso 1893/1894 y se matriculó en $4^{\circ}$ año de Piano y $1^{\circ}$ de Armonía con los profesores Tragó y Fontanilla respectivamente. No necesitó cursar la asignatura de Solfeo, tan necesarios para el aprendizaje del instrumento, la armonía o la composición. 
Por su parte, en 1894 Pedro Fontanilla ${ }^{4}$, profesor de Armonía, deja en las actas reflejado sobre Remedios, su gran aplicación, buena disposición y aptitud en el estudio de su materia. La calificación del jurado en las actas fue de Sobresaliente.

Ese mismo curso 1894 Remedios de Selva realizó $4^{\circ}$ y $5^{\circ}$ año de Piano con el profesor Tragó, siendo la Censura del jurado de Sobresaliente y Notable respectivamente, además realizó el examen de ambos cursos el mismo día 5 de junio.

El diario La Gran Vía de Madrid publica la relación de alumnas y alumnos premiados en los concursos públicos del año 1895, donde Remedios de Selva consigue accésit ${ }^{5}$ en piano.

Durante el curso 97-98 supera con éxito $2^{\circ}$ y $3^{\circ}$ de Composición y obtiene Sobresaliente en el $7^{\circ}$ curso de Piano. Así, en la Revista Bellas Artes del 22 de noviembre de 1898, en su número extraordinario dedicado a la Escuela Nacional de Música y Declamación en el día de la distribución de premios, consta un segundo premio de piano para Remedios de Selva Y Torre. Esta revista semanal se ilustra con algunas fotos de alumnas premiadas ${ }^{6}$. Estos actos de entrega de premios eran "una auténtica exhibición, con discursos, actuaciones de los pre-

4. La prensa de la época así lo definía: "Joven maestro de gran porvenir, que ya tiene sentada una justa reputación como armonista y profesor. Persona de cultura nada común, es el prototipo del artista moderno. La Dirección de LA GRAN VÍA no olvidará nunca las atenciones que tuvo para nosotros el distinguido secretario del Conservatorio".

"Escuela Nacional de Música y Declamación". La Gran Vía de Madrid 127 (14 de diciembre de 1895), p. 13.

5. En certámenes científicos, literarios o artísticos, recompensa inferior inmediata al premio (Real Academia Española, RAE)

6. "Hoy, día de Santa Cecilia, abogada del divino arte, celebra esta Escuela el acto solemne de la repartición de premios a las alumnas y alumnos que los han obtenido en el pasado curso de 1897-98.

Día de júbilo, de júbilo inmenso es el de hoy para cuantos se preocupan del desarrollo artístico de España y para los que aspiran a continuar sus gloriosas tradiciones en cuanto al Arte se refiere.

Galardón de los premiados, acicate y estímulo de los menos estudiosos, orgullo de loa profesores, satisfacción íntima é inmensa de los padres; premio al trabajo, al estudio y la constancia; ejemplo vivo de lo que representa y vale una vocación bien definida, cuando encuentra maestros que saben guiarla y dirigirla al supremo fin; todo eso y algo más que palpita hoy en muchos corazones, pero que sería imposible de describir al más experto de los psicólogos, representa y vale la fiesta de hoy.

La Escuela Nacional de Música y Declamación, si no es un modelo de análogas instituciones, tiene en cambio un profesorado idóneo, perito, técnico, por decirlo así, y que constituye un claustro de verdaderos maestros. De él mejor que de ningún otro pudo decir el crítico francés que había logrado 'unir en una perfecta educación los principios pedagógicos de Pestalozzi y Foebel con los musicales de Bertini'.

Con el método de Eslava, decimos nosotros, y con los de tantos talentos y genios como han enseñado desde aquellas cátedras.

BELLAS ARTES, al publicar hoy los retratos de las alumnas y alumnos premiados, envía a todos ellos su más sincera felicitación.

Sirva ella de estímulo a los retrasados. Labore est virtus a trabajar que el trabajo es virtud, y sed, alumnos del Conservatorio, dignos de vuestros profesores, de esos maestros que os educan en el culto del arte; de esos profesores a quienes, en este día de júbilo, día de la angélica pianista, enviamos el testimonio de nuestra veneración y respeto". 
miados y la asistencia de relevantes figuras de la sociedad madrileña (y española) del momento" (Hernández Romero, 2019, p.108)

Siguiendo a Hernández Romero (2019), las obras de concurso en piano eran diferentes para en función del género. En 1898, la obra requerida para los alumnos que finalizaban $7^{\circ}$ curso de piano fue Capricho en la menor, op.33 de Mendelssohn, mientras que las alumnas aspirantes debían interpretar el primer tiempo del Concierto en sol menor del mismo compositor. No ocurría lo mismo con el repertorio que debía interpretar el alumnado durante el curso, que era independiente del sexo y diferente para cada estudiante, en función suponemos, de sus necesidades o capacidades, aunque dentro los programas previstos en cada curso. Aun así, solían interpretar los mismos estudios (Cramer, Cerny, Clementi y Moscheles), al igual que ocurría con las fugas de Bach.

En este mismo año, 1898, Remedios de Selva, junto con tres alumnos más de la Escuela Nacional de Música y Declamación, se dirigen nuevamente al director, Ildefonso Jimeno de Lerma, para continuar sus estudios de $4^{\circ}$ y $5^{\circ}$ curso de Composición con el Maestro Tomás Fernández Grajal "pudiéndose agregar a esta razón el natural cariño que al cabo de tres años se creó entre dicho Sr. y los abajo firmantes, además de estar identificados en un todo con su sistema de enseñanza y régimen establecido" ${ }^{\prime 8}$. La respuesta del director de la Escuela fue la de no acceder a dicha petición con un "hasta nueva orden aténganse a lo dispuesto"

Finalmente, Remedios de Selva se matricula de $4^{\circ}$ curso de Composición con Emilio Serrano $^{10}$. Podemos comprobar en el acta de la asignatura que Remedios de Selva no se presentó al examen final, y tampoco parece que asistiera a ninguna

Tolosa, M. A., "Escuela de Música y Declamación". Bellas Artes Número extraordinario (22 de noviembre de 1898), p. 5.

7. Hernández Romero, N., Formación y profesionalización musical de las mujeres...

8. Documentación custodiada en el Archivo administrativo histórico del Conservatorio Superior de Madrid.

9. Documentación custodiada en el Archivo administrativo histórico del Conservatorio Superior de Madrid.

10. "Compositor, pianista, director de orquesta y profesor. La figura de Emilio Serrano es de gran trascendencia en la historia musical del siglo XIX español, no sólo en cuanto al valor intrínseco de su producción musical, sino también en relación con la amplia labor pedagógica desarrollada desde su puesto como maestro de composición del Conservatorio madrileño, al que accedió en 1894, tras el fallecimiento de Arrieta. Desarrolló una importante actividad de creación lírica en el mundo de la ópera, estrenando cinco óperas, cuatro en el Teatro Real-Mitríades, 1882; Doña Juana la Loca, 1890; Irene de Otranto, 1891, y Gonzalo de Córdoba, 1898- y La maja de rumbo, estrenada en el Teatro Colón de Buenos Aires. Por el contrario, sus incursiones en el género zarzuelístico son escasas, destacando su colaboración con Francisco Alonso en La bejarana, una de las últimas obras de su catálogo". (Casares, 2003, p. 753). La prensa de la época así lo definía: "Discípulo de Eslava y Arrieta y de su propio padre Antonio Santamaría, que conoce el legado de una enseñanza anclada en formas líricas antiguas. La prensa de la época así lo definía: "Autor de óperas españolas, compositor y profesor de mérito; desempeña hoy la misma cátedra que tantos años ocupó el ilustre Arrieta. La moderna generación de músicos espera mucho de las condiciones del maestro Serrano". 
clase de dicho profesor. No sabemos el motivo de su abandono en la asignatura de Composición. Emilio Serrano así hace constar en las actas el propio desconocimiento sobre dicha alumna. Llama la atención que, de los seis estudiantes matriculados en este mismo curso y con el mismo profesor, cinco varones y una mujer (Remedios de Selva), cuatro son alumnos desconocidos para éste y tan sólo uno, se presenta al examen final con jurado, aprobando dicha asignatura ${ }^{11}$.

En cuanto a la vida privada de Remedios de Selva, sabemos que residió con su padre en Madrid en la calle Leganitos, situada en el céntrico barrio madrileño de Argüelles (tal y como consta el padrón a primeros de diciembre del año 1900). Dicha casa no era propiedad de Constantino de Selva, el cual pagaba 65 pesetas al mes en concepto de alquiler. Una cantidad considerable en aquellos años que sólo podían permitirse las personas adineradas o miembros de la burguesía madrileña.

En 1907, tras la muerte de su padre, Remedios de Selva se empadrona en el mismo domicilio que su tía, Concepción Selva López Osorio, en el barrio de San José. Posteriormente ambas se mudan a la calle Santa Isabel en el barrio de Torrecilla. De 1915 a 1935 Remedios permanece en el mismo domicilio situado en la calle Pelayo ${ }^{12}$.

Remedios de Selva era soltera ${ }^{13}$ y una mujer de carácter, según se describe en la sección de sucesos de la prensa. El sábado 2 de septiembre de 1911 varios periódicos relataron la siguiente noticia:

\section{Sucesos de Madrid}

Las mujeres de temple.

Manuel Delgado Villalonga ${ }^{14}$ requirió ayer el auxilio de los guardias de Seguridad números 785 y 527 para que detuvieran a su novia Remedios Selva Torres, la cual, al apercibirse de la maniobra, dio una bofetada a cada uno de los mencionados agentes de la autoridad, encerrándose después en su casa, calle de Santa Isabel, número 30, tercero, de donde se negó a salir. (La Mañana, 1911, p. 2) ${ }^{15}$

"Escuela Nacional de Música y Declamación". La Gran Vía de Madrid 127 (14 de diciembre de 1895), p. 11.

11. Actas de exámenes, documentación custodiada en el Archivo administrativo histórico del Conservatorio Superior de Madrid.

12. Archivo de Villa del Ayuntamiento de Madrid.

13. Padrón del Archivo de Villa en Madrid

14. El 5 de mayo de 1938 falleció en Buenos Aires don Manuel Delgado Villalonga, artista pintor, a los 64 años. Hermanos, los Condes de Albarreal de Tajo, sor Josefina (esclava del Sagrado Corazón en Belgrano, Argentina). Primo hermano, don Joaquín Delgado, presidente de la Audiencia de Palma (Mallorca). Movimiento Nobiliario 1931-1940. Año 1938. Por José de Mayoralgo y Lodo, Conde de los Acevedos.

15. "Sucesos de Madrid". La Mañana (2 de septiembre de 2011), p. 2. 


\section{Sucesos de Madrid}

¡Vaya una hembra!

Remedios Selva Torres es una hembra valiente de verdad. Una pareja de Orden público que acudió a detenerla a instancia de su novio, Manuel Delgado, sufrió sonoras bofetadas de la Remedios, que después continuó tranquilamente su camino. (Heraldo de Madrid, 1911, p. 2) ) $^{16}$

\section{Sucesos}

\section{Una bravía}

Manuel Delgado Villalonga requirió el auxilio de la pareja de Orden público para que detuviesen a su novia Remedios Selva Torres, de treinta y cuatro años de edad; pero esta, una hembra de trapío ${ }^{17}$ que no se amilana tan fácilmente, atizó sendas bofetadas a los del Orden.

Y como la cosa más natural del mundo les "miró al soslayo fuese y no hubo nada". (El Liberal, 1911, p. 5) ${ }^{18}$

Previamente a este suceso, Manuel Delgado Villalonga se vio envuelto en problemas con la justicia por el impago de ciertos trabajos que fueron realizados en su estudio de pintura. Fue condenado en 1909 y la sentencia fue publicada en el Boletín Oficial de la Provincia de Madrid al encontrarse éste en estado de rebeldía. Esta situación se produce cuando el demandado no comparece a la citación. ${ }^{19}$

16. "Sucesos de Madrid". Heraldo de Madrid (2 de septiembre de 2011), p. 2.

17. En el lenguaje taurino se utiliza para referirse a la buena planta de un toro de lidia.

18. "Sucesos". El Liberal (2 de septiembre de 2011), p. 5.

19. PROVIDENCIAS JUDICIALES. Juzgado de primera instancia. Hospital. En los autos de menor cuantía que se siguen a instancia de doña Teresa González y García que se defiende en concepto de pobre contra D. Manuel Delgado Villalonga, se ha dictado la sentencia cuya cabeza y parte dispositiva es del tenor siguiente:

Sentencia: En la villa y corte de Madrid a 18 de Septiembre de 1908, el señor don Mariano Luján y Tejada, juez de primera instancia del distrito del Hospital; habiendo visto los presentes autos de juicio declarativa de menor cuantía seguidos a instancia de doña Teresa González García, mayor de edad, soltera, sin profesión especial, como madre natural del menor Juan Manuel Mayor González, representada por el procurador D. Gregorio Fernández Voces y defendida por el abogado D. Baldomero de los Santos, contra D. Manuel Delgado Villalonga, de igual domicilio, el cual se encuentra declarado en estado legal de rebeldía, sobre pago de cierta cantidad.

Fallo: que debo condenar y condeno a D. Manuel Delgado Villalonga, a que en el término del tercer día de ser firme esta sentencia pague a doña Teresa González y García, como madre del menor Juan Manuel Mayor González, la suma de 747 pesetas que es su deber, resto del importe de los trabajos y materiales invertidos por éste en la restauración de varios muebles del estudio de pintura del demandado, con más el interés legal desde la interpelación judicial, sin hacer especial condena de costes. Así por esta mi sentencia que además de notificarse en Estrados por la rebeldía del demandado, se publicará en el Boletín Oficial de la Provincia a fin de que sirva de notificación al demandado rebelde don Manuel Delgado Villalonga, pongo la 
Remedios de Selva provenía de una familia importante y adinerada, esto le posibilitó estar muy bien relacionada. No sólo no tuvo consecuencias abofetear a dos agentes del orden público, algo que sólo podría permitirse alguien con influencia, sino que también el trato de la prensa resulta cuanto menos llamativo. La lectura de los titulares anteriores (Las mujeres de temple, ¡Vaya una hembra! y Una bravía) muestran a nuestra compositora como una heroína y la reacción contra el intento de su detención como si de una hazaña se tratase.

Debemos añadir también que su red de relaciones le llevó a conocer al Rey de España Alfonso XIII, tal y como describe la sección Vida Palatina del periódico La Mañana:

\section{VIDA PALATINA}

Audiencias del Rey.

Después de despachar con el presidente del Consejo y los ministros de la Gobernación y Hacienda, el Rey recibió en audiencia a una Comisión del Consejo Superior de Emigración, presidida por el marqués de Pilaros.

También fueron recibidos por el Monarca doña Remedios de Selva Torre, D. Carlos Mendoza y D. Álvaro Alcalá Galiano, que dio gracias a S. M. por la concesión del título de marqués de Castel Bravo.

Cumplimentaron al Soberano el general D. Francisco Borbón, Ios duques de Híjar y Bivona, el marqués do la Ribera de Tajuña y el director de las Reales Caballerizas, Sr. Cienfuegos. (La Mañana, 1918, p. 3$)^{20}$

Desconocemos qué relación pudo tener Remedios de Selva con Álvaro Alcalá-Galiano y Osma al que acompañó a la rehabilitación por el rey Alfonso XII del título nobiliario de marqués de Castel Bra$\mathrm{VO}^{21}$.

presente que firmo en Madrid a 12 de Diciembre de 1908.=El escribano, García del Rivero. (Núm. 4.144) (C.-284.) (Boletín Oficial de la Provincia, 1908, p. 4)

20. "Vida Palatina". La Mañana (5 de junio de 2018), p. 3.

21. "Accediendo a lo solicitado por D. Álvaro Alcalá Galiano y Osma; teniendo en cuenta lo prevenido en el Real decreto de 27 de Mayo de 1912; de conformidad con los dictámenes de la Diputación de la Grandeza de España y Comisión permanente del Consejo de Estado; a propuesta de Mi Ministro de Gracia y Justicia, y de acuerdo con Mi Consejo de Ministros, Tengo en rehabilitar a favor de dicho señor, sin perjuicio de tercero de mejor derecho, el Tituló de Marqués de Castel Bravo del Rivero, para sí, sus hijos y sucesores legítimos. Dado en Palacio a veintitrés de Mayo de mil novecientos dieciocho. ALFONSO: Mi Ministro de Gracia y Justicia, Álvaro Figueroa".

"Ministerio de Gracia y Justicia". Gaceta de Madrid (25 de mayo de 1918), p. 512. 


\section{Breve historia del Conservatorio de Madrid}

El primer Conservatorio de Música inaugurado en España fue el Real Conservatorio de Música de María Cristina en Madrid en el año 1830, regido por el Reglamento interior de 1831.

Con el Real Decreto de 14 de diciembre de 1857, se sustituye su denominación por la de Real Conservatorio de Música y Declamación. No es hasta la aprobación de este Real Decreto, que se prohíbe expresamente la asistencia de las alumnas a determinadas asignaturas. Además, los estudios se dividen en Superiores (que conducen al Título de maestro Compositor) y de Aplicación (Profesor del Real Conservatorio). Según Hernández Romero (2011)²2, "las discípulas sólo podían cursar asignaturas (...) necesarias para obtener los títulos de canto, de piano o de arpa, negándoles el acceso a los estudios superiores" (pp. 8-9).

Mediante el Decreto y Reglamento de 15 y 22 de diciembre de 1868, se disuelve el antiguo Real Conservatorio de Música y Declamación y se crea la Escuela Nacional de Música. Queda de esta manera anulada la Declamación como materia en dicho centro. Aun así, son numeroso los documentos que se refieren a este centro como Escuela Nacional de Música y Declamación, o Escuela Nacional de Declamación ${ }^{23}$.

Finalmente, el centro vuelve a cambiar su denominación por la de Conservatorio de Música y Declamación mediante el Reglamento de 14 de septiembre de $1901^{24}$.

Las especialidades impartidas en la Escuela Nacional de Música con el Reglamento de 1868 eran Solfeo, Canto, Instrumentos, Armonía y Composición. Como ya hemos comentado anteriormente, no se imparte Declamación en el Conservatorio y disminuyen drásticamente las especialidades instrumentales a impartir.

Según Ros (2002): "Se reducen las asignaturas a las que tienen acceso las mujeres: Solfeo, Canto y Piano. Con ello se vuelve a negar el acceso a Arpa,

22. Hernández Romero, N., "Educación musical y proyección laboral de las mujeres en el siglo XIX: el Conservatorio de Música de Madrid". TRANS-Revista Transcultural de Música 15 (2011).

23. "Arrieta, profesor de composición del Conservatorio Real de Madrid desde 1857, fue nombrado director en 1868, en sustitución a Hilarión Eslava, manteniéndose en este cargo hasta la fecha de su muerte en 1894... Entre otros logros de la etapa Arrieta podemos citar que se reanudan las clases de declamación, integrándose en 1874 en la plantilla del centro Matilde Díez, y se estimulan los contactos con centro europeos, sobre todo el Conservatorio de Bruselas".

Cortizo, M. E., "La formación de Chapí en el Conservatorio de Madrid: el magisterio de Arrieta", V. Sánchez, J. Suárez-Pajares, y V. Galbis. (Eds.), Ruperto Chapí. Nuevas perspectivas (2) (pp. 81-97). Valencia 2012.

24. Ros, M. A. S., "Rol modélico del conservatorio de Madrid II (1868-1901)". Ensayos: Revista de la Facultad de Educación de Albacete 17 (2002), pp. 149-176. 
especialidad que, por otra parte, deja de constar en el cuadro de especialidades del Centro" (p. 152).

Sin embargo, sabemos por el expediente académico custodiado en el Archivo del actual Conservatorio Superior de Madrid, que Remedios de Selva y Torre cursó estudios de Solfeo, Piano y Composición de forma oficial, tal y como veremos más adelante, y que superó con éxito segundo y tercer curso de Composición durante el curso 97-98. También estuvo matriculada de cuarto año de Composición durante el curso 98-99, aunque las actas reflejan dicha materia sin calificar ${ }^{25}$.

En estas mismas actas se observa cómo era algo excepcional que una mujer cursase estudios de composición. De hecho, en el primer año de composición del Sr. Grajal, durante el curso 1896-1897, Remedios de Selva era la única mujer matriculada, mientras todos los demás eran alumnos varones. En este mismo curso académico, no había ninguna otra mujer cursando segundo de composición y tan solo una, en tercero, con este mismo profesor. ¿Se trataba entonces del incumplimiento de la normativa? ¿Se hacían excepciones por algún motivo $\mathrm{o}$, en realidad y en la práctica general las mujeres podían realizar la asignatura de composición?

El estudio de la composición por parte de las mujeres suscitó un intenso debate. Se trató de una asignatura prohibida para éstas, aunque no siempre fue así. En 1831, con la puesta en marcha del Conservatorio de Madrid, aparecen las primeras alumnas matriculadas.

Fue a partir de 1857 cuando comienzan las verdaderas restricciones para las alumnas del conservatorio, siendo "la primera vez que un reglamento dictamina en qué asignaturas podían ingresar alumnos de ambos sexos, solo correspondientes a los Estudios de aplicación" (Hernández Romero, 2019, p. 85) 26.

La prohibición de acceso a las mujeres en los Estudios superiores supuso un paso atrás en los derechos adquiridos en la etapa anterior y, como ya se ha mencionado anteriormente, con la llegada del reglamento de 1868, se redujo aún más la posibilidad de matricularse en otras asignaturas que no fuesen solfeo, canto y piano.

Fue con el reglamento de 1871 cuando se volvió al estado inicial en cuanto a la igualdad de oportunidades para las alumnas. Este reglamento solo otorgaba el diploma de Maestro compositor, siendo el resto de los estudios, justificados con certificados que expedía el propio centro. Hernández Romero (2019) afirma que "podían matricularse alumnos de ambos sexos en todas las

25. Actas de exámenes Archivo administrativo histórico del Conservatorio Superior de Madrid.

26. Hernández Romero, N., Formación y profesionalización musical de las mujeres en el siglo XIX: El Conservatorio de Madrid. Alcalá de Henares 2019. 
clases de la Escuela, asistiendo a distintas horas cada uno". Sin embargo, esta medida parece que no supuso un cambio sustancial en las elecciones de las alumnas.

\section{Actividad pedagógica}

De la actividad pedagógica de Remedios de Selva conocemos muy poco. Por supuesto, es difícil de documentar una posible práctica de instrucción individual de carácter privado debido a la ausencia de contratos, aunque no por ello debemos restarle importancia. Tampoco tenemos constancia, por el momento, de si pudo impartir clases en diversos centros como academias o asociaciones.

En 1909 y 1911 el Anuario del Comercio de la Industria de la Magistratura y de la Administración de España, sus colonias Cuba Puerto Rico y Filipinas, Estados Hispanoamericanos y Portugal, en su sección Toledo (Part. Jud. De Talavera de la Reina $)^{27}$, nombra a Remedios de Selva en la sección de Profesores de Música. No nos aporta ningún otro dato dicho documento, que nos lleve a determinar qué materias de música enseñaba o dónde.

Como ya hemos apuntado anteriormente, la enseñanza privada era algo habitual, e incluso los propios profesores del Conservatorio de Madrid la ejercían. Esto quedó reflejado en las distintas solicitudes de permisos que éstos realizaron al hacerse obligatorio el requerimiento por la administración.

Por su parte, algunas de las alumnas que pasaron por el Conservatorio de Madrid durante el siglo XIX y principios del XX, ejercieron la docencia en Sociedades Musicales, academias de música privadas, colegios femeninos, o en instituciones culturales como el Ateneo de Madrid. Lamentablemente, en este último, no se ha podido encontrar documentación relacionada con Remedios de Selva, debido a la desaparición de los fondos después de la Guerra Civil Española.

Podemos deducir que algunas de sus obras escénicas están compuestas para ser representadas por niñas o niños, posiblemente en algún colegio femenino y/o masculino, como es el caso de Niní y Beatriz, Zarzuela en un acto para niñas solas o Una jira, Sainete en un acto y dos cuadros para niños solos.

Existen precedentes no muy lejanos, casi contemporáneos a Remedios de Selva, como es el caso de Pilar Contreras, quien además de componer zarzuelas, óperas o himnos, tiene una obra dramática dirigida al público infantil

27. Anuario del Comercio de la Industria de la Magistratura y de la Administración de España y sus Colonias. (1909). Toledo (part. Jud. Talavera de la Reina).

Anuario del Comercio de la Industria de la Magistratura y de la Administración de España y sus Colonias. (1911). Toledo (part. Jud. Talavera de la Reina). 
con un carácter didáctico y a la vez moralizante y fundamentalmente para ser representadas en colegios ${ }^{28}$.

En cuanto a la obra pianística de Remedios de Selva, comprende mazurcas, marchas y valses de claro corte chopiniano, que pudieron ser compuestas para la enseñanza del piano y pensada para cursos medios, dado que carecen de dificultad técnica. Cabe la posibilidad, debido a la juventud con la que compuso alguna de estas obras, que fueran trabajos realizados dentro de la misma asignatura de Composición. Algunas de estas obras son compuestas durante su estancia en el Conservatorio, como, por ejemplo, la improvisación para piano El motín de Canuto o la muerte de un gato, editada en 1897.

También sus piezas religiosas, casi siempre compuestas para coro al unísono con acompañamiento de órgano, o voz sola, parecen adaptarse bien una la tesitura de voces blancas. Aunque, además, realiza obras polifónicas como Salve Regina para cuatro voces con acompañamiento de piano u órgano y de la que no podemos datar con exactitud la fecha de composición.

En 1915, Remedios de Selva presenta su instancia y es admitida a oposiciones de Profesor Supernumerario de Piano vacante en el Conservatorio de Música y Declamación de Madrid. Así consta en la lista de aspirantes publicado en la Gaceta de Instrucción Pública y Bellas Artes el 1 de septiembre de ese mismo año, junto, entre otros, a Emiliana de Zubeldía ${ }^{29}$.

28. En cuanto a su obra dramática de carácter didáctico, Pilar Contreras cultivó varios géneros como zarzuelas (Muñecos y muñecas o Las niñas del bazar), juguetes cómicos (¡Qué cosas tienes, Benita! y sainetes (Los pícaros intereses o Domésticas y sin domesticar). Pero en realidad su obra más importante es un libro en seis tomos realizado en colaboración con Carolina de Soto y Corro, Teatro para niños: diálogos, monólogos, comedias, apropósitos y revistas en un acto, en prosa y verso, para escuelas, colegios y salones (1910-1917).

29. "Nacida en Navarra (...) Emiliana marchó a la Schola Cantorum de París, donde estudió composición en la cátedra de Vicent d’Indy. En París la autora pudo conocer otra realidad de las mujeres, que ya habían conseguido algunos derechos, y actuaban y se comportaban de manera distinta a sus referentes españoles (...) Estos estudios musicales se vieron truncados con la muerte de su padre, lo que le obligó a regresar a Pamplona.

Durante la década de 1920 regresó a París, donde trasladó su residencia, y trabajó como pianista en los ensayos de los Ballets Rusos de Diaguilev, hecho que nuevamente le une con la vanguardia y la modernidad. La música que escribió Emiliana en estos años es de claro corte impresionista. Utiliza además elementos del lenguaje de vanguardia, como la bitonalidad en La muñeca de vidrio, o el atonalismo en su Sinfonía natural. A finales de la década de 1920 realizó un viaje por América latina que influiría en su producción musical (...) Finalmente trasladó su residencia a América, muchos años antes de que lo hiciera masivamente los compositores españoles tras la Guerra Civil. Encontramos a Emiliana en América en los primeros años 1930, viviendo en Brasil, México o Nueva York. Emiliana es la compositora más viajera, cosmopolita e interesada en las vanguardias de estos primeros años de siglo. La autora llegó a experimentar con tipos de armonía y afinaciones nuevas, basadas en las teorías de Novaro (...) En la última etapa de su vida dedicó gran parte de su 
Por otro lado, y aunque no existe constancia de que Remedios de Selva estudiase Canto en el Conservatorio de Madrid, sin embargo, la Gaceta de Instrucción Pública y Bellas Artes de 14 de febrero de 1917, en su apartado sobre la administración central del día 5 de febrero, nombra a Remedios de Selva como aspirante a la convocatoria de oposiciones de la Cátedra de Canto del Real Conservatorio de Música y Declamación ${ }^{30}$.

Pero después de una revisión de la serie documental de Asuntos Generales 1916-1917 en el Archivo Histórico del Conservatorio Superior de Madrid, sólo se han localizado varios oficios referentes al nombramiento de Luisa García Rubio como profesora numeraria de Canto. No existe coincidencia alguna con la lista de aspirantes anteriores y no se ha encontrado referencias a Remedios de Selva en esa serie.

Podemos afirmar por lo tanto que también era cantante, otra faceta desconocida de nuestra compositora. Probablemente desarrolló estos estudios de forma privada y paralela a los oficiales de piano y composición en el Conservatorio de Madrid.

Sabemos que ejerció como profesora de canto, gozando de buena fama. Algunos de sus alumnos más destacados eran acompañados al piano por ella misma en sus conciertos. Al menos así lo reflejan diferentes diarios:

Programa de radiodifusión para hoy Madrid (...) De diez a doce de la noche. Gran concierto, por los notables artistas señor Rodrigo-Cid

esfuerzo a dar clase de piano y, sobre todo a la dirección de coros, en la Universidad de Sonora de Hermosillo (México).

Palacios, M., "Música y género en la España de principios del siglo XX (desde 1900 hasta la posguerra y el exilio)", Álvarez, González, Gutiérrez, Marcos (Eds.), Compositoras Españolas. La creación musical femenina desde la Edad Media hasta la actualidad. Madrid 2008, pp. 81-82

30. Dirección general de Bellas Artes.

Disponiendo se publique en este periódico oficial la lista de los aspirantes admitidos a las oposiciones a la Cátedra de Canto, vacante en el Real Conservatorio de Música y Declamación:

Ilmo. Sr.: en cumplimiento de lo preceptuado en el art. 14 del Reglamento de oposiciones de 8 de abril de 1910,

Esta Dirección general ha resuelto que se publique en la Gaceta de Madrid la lista de los señores aspirantes que por haber justificado reunir las condiciones exigidas en la convocatoria, han sido admitidos a la práctica de los ejercicios, y que son los siguientes:

D. Juan Gamisans y Arabi, D. ${ }^{a}$ Remedios de Selva y Torre, D. Emilio García Soler, D. ${ }^{a}$ María del Socorro Segura y Oliva, D. Pedro Pardo Abarca, D. Francisco Pérez Ríos, D. Arturo Camacho y Velasco, D. Juan Ibarra Rodríguez, D. ${ }^{a}$ Martina Hurtebisedit Delaborde, D. ${ }^{a}$ Concepción Martín San Miguel, D. ${ }^{a}$ María Pastora Ortiz, D ${ }^{a}$ Emilia Martínez y Ortiz de Urbina, D. ${ }^{a}$ Felisa Fernández Pérez y D. a María Fernández Lamarca".

"Administración Central". Gaceta de Instrucción Pública y Bellas Artes (14 de febrero de 1917), p. 109. 
(tenor) y Teodoro de la Cruz (barítono), acompañados al piano por su profesora, doña Remedios Selva y Torre. Primera parte: «Marina» (dúo de tenor y barítono), Arrieta, por el tenor y el barítono; «Carmen» (romanza de la flor, a petición), Bizet, por el tenor; «El guitarrico. (Jota), Soriano, por el barítono, y «Lo que son tus besos» (canción). Prado, Prats y R. de Selva, por el barítono.

Crítica y proselitismo musicales, por D. Félix del Real Torralba.

(La Libertad, 1925, p. 2 y El Imparcial, 1925, p. 7) ) $^{31}$

Por su parte, el diario La Libertad en su crítica al concierto ofrecido previamente, señala que "la distinguida profesora de canto doña Remedios Selva y Torre acompañó al piano a sus aventajados discípulos el tenor Rodrigo-Cid y el barítono Teodoro de la Cruz" (La Libertad, 1925, p. 2) 232.

\section{Recepción periodística de la obra dramática}

Tenemos constancia de los estrenos de algunas de las obras dramáticas de Remedios de Selva. El 12 de mayo de 1909, el diario Correspondencia de España, en su sección El teatro en Provincias, informa sobre el estreno de la Zarzuela Lo que el dinero no compra, de Remedios de Selva ${ }^{33}$.

El 17 de mayo de 1909, el Heraldo de Madrid, realiza una pequeña crítica sobre la obra ya estrenada:

Alicante-En el teatro $\mathrm{Nuevo}^{34}$ se ha verificado con excelente éxito el estreno da la zarzuela titulada Lo que el dinero no compra, letra del conocido escritor D. José de Campos, música de la señorita Remedios da Selva, sobrina del Insigne Chapí.

31. "Radiotelefonía". La Libertad (17 de marzo de 1925), p. 2; "Radiotelefonía". El Imparcial (17 de marzo de 1925), p. 7.

32. "Radiotelefonía". La Libertad (18 de marzo de 1925), p. 2.

33. "ALICANTE, En esta semana se verificará en el Teatro Nuevo el estreno de la Zarzuela titulada Lo que el dinero no compra, cuyo libreto es original de D. José de Campos y la música de la señorita doña Remedios de Selva, comprovinciana nuestra y sobrina del eximio maestro Chapí".

"El teatro en provincias". Correspondencia de España (12 de mayo de 1909), p. 4.

34. Teatro Nuevo. Este teatro fue el nuevo nombre que se le dio al Teatro Recreo Alicantino en 1907 y que ya funcionaba desde 1905, situado en la calle de Jorge Juan. En él debutó la célebre Milagritos Gorgé con El cabo primero y Una vieja. Registramos en este teatro una dilatada vida escénica, pues anotamos muy diversas compañías líricas desfilando por su escenario hasta 1912. Después, y hasta 1937, se dedica a otros géneros y en los últimos años representa gran cantidad de teatro en valenciano. Las compañías líricas que en él actuaron fueron preferentemente de base local, siendo frecuente la de Enrique Poveda y Francisco Fons, en el que actuaba Ernestina Fons, hija del anterior. El 30 de noviembre de 1908 hizo su debut con la Compañía de José Gil Y Paco Guillem, el tenor alicantino Roque Úbeda con Bohemios. (Navarro, 2007, p. 396). 
Tanto la letra como la música gustaron extraordinariamente.

El público aplaudió con entusiasmo la nueva producción y prodigó grandes ovaciones a los intérpretes, los cuales hicieron una esmeradísima labor. (Heraldo de Madrid, 1909, p. 4) ${ }^{35}$

Sabemos de otro estreno teatral de Remedios de Selva. En la tesis Historia del Teatro olvidado: la Revista (1864-2009), Montijano (2009) afirma: "Nuevos títulos se suceden sin un ápice de continuidad construyendo el brillante pasado de este género teatral tan español: (...), La Tranquilidad, pensión para señoras (1926), con letra y música de Remedios de Selva y Torre" (p. 732)

Debemos aclarar que la denominación de zarzuela se otorga, en numerosas ocasiones, a una pieza por el mero hecho de ser lírica y no tiene por qué referirse un subgénero específico de zarzuela breve. Es por esto, que podemos encontrar distintas denominaciones para una misma pieza musical. A su vez, la revista es el subgénero al que se le ha dado un mayor número de nombres diferentes de una forma caprichosa. Sirvan de ejemplo el acontecimiento, apropósito, apuntes, boceto, fantasía, humorada, locura, ópera, pasillo o viaje. Esto nos lleva directamente al problema de las denominaciones en la tipología de las formas teatrales breves y que veremos más adelante.

\section{Escritos impresos en publicaciones periódicas}

Además de su actividad musical como profesora de canto, pianista y compositora, una faceta curiosa de Remedios de Selva fue su contribución a la mejora de la calidad de vida de los invidentes. Remedios de Selva escribía con frecuencia para la revista Los ciegos, Revista Mensual Tyflofila Hispanoamericana dirigida por Antonio Las Heras Hervás ${ }^{37}$.

Entre los escritos de Remedios de Selva para esta revista, encontramos artículos que tratan el Renacimiento musical italiano ${ }^{38}$ o sobre música profana ${ }^{39}$.

35. "Espectáculos". Heraldo de Madrid (17 de mayo de 1909), p. 4.

36. Montijano, J. J., Historia del Teatro olvidado: la Revista (1864-2009) (tesis doctoral). Granada 2009.

37. El diario La Mañana 12 de agosto de 1917 la califica así: "Aparte del notable mérito de sus trabajos, hay en esta simpática publicación un gran valor ideal, digno de toda atención; ella persigue la rehabilitación social de los ciegos, extinguiendo la mendicidad de los mismos. Cosas que se propone conseguir fomentando sus actividades profesionales y recabando para ellos la justa atención que merecen."

"Noticias Generales". La Mañana (12 de agosto de 1917), p. 5.

38. Sobre la importancia de Palestrina como "fundador o creador de la música moderna del género religioso".

De Selva, R., "Música Italiana". Los ciegos 10 (noviembre de 1917), pp. 8-9.

39. "En el siglo XVII la música dramática adquirió su carácter propio y peculiar con la invención o aplicación del recitativo, o sea la música declamada, que fue la que dio a la tragedia 
También escribe sobre Fray Pablo Nasarre ${ }^{40}$, monje franciscano, ciego de nacimiento, que nació y murió en Zaragoza (1664-1730). Fue uno de los principales teóricos españoles, autor de la obra más completa sobre teoría musical barroca escrita en España. Además, fue profesor de armonía y contrapunto e importante organista en su época. Fue alumno de otro ciego, Pablo Bruna ${ }^{41}$, sobre el cual, Remedios de Selva dedica otro artículo en la revista de marzo de 1922. Pablo Bruna (1611-1679), también conocido como el ciego de Daroca, fue uno de los mejores organistas españoles.

Con motivo del fallecimiento de Carlos Terraza de Vesga ${ }^{42}$, que patentó un renovador, sistema "terraza", aplicable a la bandurria, laúd y guitarra, dedica otro escrito en 1921.

El origen del nombre Cecilia, da lugar a La ciega guía de las catacumbas de $R_{0 m a}{ }^{43}$. En la entrega de abril en 1921 Selva hace una pequeña biografía sobre Fray Pedro de Ureña ${ }^{44}$, ciego desde su nacimiento en 1580, monje cisterciense, músico, matemático, astrólogo y reformador del canto gregoriano.

Al revisar la prensa madrileña de la época, nos encontramos con el anuncio en el Heraldo de Madrid del 17 de junio de 1917 de una Exposición Nacional de Trabajos de Ciegos $^{45}$. Entre las obras recibidas para la tómbola, cuadros, libros o diversos trabajos, se encuentran diversas obras musicales de Manzanares, Antón Casaseca, P. Villalba, Granados, Félix da Santos, Vivó, Julio Gómez, Ouride, J. Aroca, Bretón, Saenz do Arana, Calleja, P. José Antonio de S. S. ${ }^{46}$, Usandizaga, Mediavilla, Arruga, Casa Editorial Faustino Fuentes y Remedios de Selva y Torre.

El 23 de noviembre de 1918, el Diario Universal anuncia un congreso internacional para el mejoramiento de la situación de los ciegos. Las bases de dicho

lírica su verdadera y definitiva constitución".

De Selva, R., "Música Profana". Los ciegos 10 (noviembre de 1917), p. 9.

40. De Selva, R., "Ciegos Ilustres: Fray Pablo de Nasarre". Los ciegos 44 (enero de 1921), pp. 5-7.

41. "Ciegos ilustres: Pablo Bruna", anunciado en la prensa el sumario de dicha entrega. "Publicaciones". Diario Universal (15 de marzo de 1922), p. 3.

42. De Selva, R., "Carlos Terraza de Vesga". Los ciegos 46 (marzo de 1921), pp. 5-7.

43. De Selva, R., "La ciega guía de las catacumbas de Roma". Los ciegos 47 (abril de 1921), pp. 6-7.

44. De Selva, R., "Fray Pedro de Ureña". Los ciegos 48 (mayo de 1921), p. 5.

45. "Con motivo del alargamiento de las obras que se están realizando en el ministerio de Estado, en cuyos salones debe verificarse esta Exposición, y con vista de lo entrado de la temporada veraniega, la Comisión organizadora de la misma ha acordado su aplazamiento hasta el próximo otoño, quedando en pie todos los ofrecimientos de conferencias, conciertos, lecturas, etc., que se tienen para la misma".

"Exposición Nacional de Trabajos de Ciegos". Heraldo de Madrid (17 de junio de 1917), p. 2

46. José Gonzalo Zulaica Arregui (San Sebastián 1886-Lacároz 1956), conocido como Padre Donostia o Aita Donostia, fue compositor, folclorista e investigador. Se ordenó sacerdote en 1908 adoptando el nombre de José Antonio de San Sebastián que posteriormente cambió por José Antonio Donostia. 
congreso se publicaron en la revista Los ciegos, cuya redacción contaba con la figura Remedios de Selva ${ }^{47}$.

\section{Obra}

La obra compuesta por Remedios de Selva podemos clasificarla en música para piano, música religiosa, música escénica y música de salón.

\subsection{La música para piano}

Al repertorio para piano encontrado hasta el momento, pertenecen sus obras más tempranas, cuando Remedios de Selva aún era alumna del Conservatorio de Madrid. Sus formas se encuadran en la tradición romántica de claro corte chopiniano. Son composiciones basadas en ritmos de danzas, mazurcas, marchas y valses, dentro de un lenguaje específicamente pianístico del siglo XIX, constituido por piezas breves, de formas libres de carácter seccional.

En cuanto a la estructura de estas obras, podemos observar que poseen una división formal muy parecida:

6.1.1. Gotas de Rocío. Mazurca para piano, Madrid, Calc. De Almagro y $\mathrm{C}^{\mathrm{a}}$, (1900). Una Introducción precede a la Mazurca y la obra finaliza con una Coda.

6.1.2. El motín de Canuto o la muerte de un gato. Marcha para piano, Madrid, Cal. A. Ruiz, (1897). Como sucede en la obra anterior, la obra comienza con una breve Introducción a la que le sigue la Marcha, después un Trío y finalmente la Coda.

6.1.3. Los Melancólicos. Tanda de Valses, para piano. Madrid, Calc. De Almagro y $C^{a}$, (1900). Consta de una Introducción cuatro Valses y una Coda.

\subsection{Música religiosa}

Dentro del repertorio de música religiosa, podemos encontrar composiciones realizadas por mujeres. Estas obras tenían como destino la Iglesia. Se trataba

47. La redacción de la revista Los ciegos compuesta por las Srtas. María del Pilar de Zubiaurre, Estrella Fontanalls, Aurora Navarro, Remedios de Selva y Torre y los señores D. Cristóbal de Castro, D. Antonio Zozaya, D. Ramon María de Pereda, D. Ángel Duran Cao, D. Mauricio Bacarisse, D. Carlos Lickefett, D. Zacarias López Debesa y D. Antonio Las Hera, publicará en breve las bases por que ha de regirse este Congreso Internacional, primero que se celebrara después de la guerra y en cuya organización se ocupa muy activamente con el fin de que tenga lugar en Madrid el próximo año.

"Noticias". Diario Universal (23 de noviembre de 1918), p. 2. 
de un ámbito mejor visto socialmente para el desarrollo de la composición femenina ya desde el siglo XIX.

Las prácticas religiosas y la participación en ritos y celebraciones públicas del culto católico eran de obligada presencia para las mujeres, y las compositoras del XIX amortizaron esta imposición creando piezas para ser interpretadas y escuchadas en la liturgia y en actos públicos religiosos de distinto tipo. (Sánchez de Andrés, 2008, p. 66) ${ }^{48}$

Algunas compositoras del siglo XIX-XX que cultivaron la música religiosa fueron Luisa Casagemas, Paulina Cabrero, Ascensión Martínez Ramírez o Soledad Bengoechea, siendo ésta última la compositora más destacada.

La obra religiosa de Remedios de Selva se compone de piezas de pequeño formato (motetes, himnos, Ave María, etc.), sencillas y pensadas para poder ser interpretadas por aficionados. Hasta el momento se han recopilado ocho obras de carácter religioso. La mayor parte de estas obras fueron editadas en 1913 y se encuentran en la Biblioteca Nacional de España. Desconocemos la fecha exacta de la composición Salve Regina para cuatro voces con acompañamiento de órgano custodiada en la Biblioteca Musical Víctor Espinós en Madrid. Tampoco sabemos si fue tolerada, como el resto del repertorio musical de Remedios de Selva, por la Comisión Censora de Música Religiosa, quien aprobaba las obras que estuvieran escritas con arreglo a las disposiciones contenidas en el Motu proprio de S.S. Pío $X$, promulgado en $1903^{49}$.

6.2.1. Ave María para tiple o tenor con acompañamiento de órgano (1913). Tolerada por la Comisión Censora de Música Religiosa.

6.2.2. Ave Verum. Himno al Santísimo para coro al unísono con acompañamiento de órgano (1913). Aprobado por la Comisión Diocesana de Madrid-Alcalá

6.2.3. Bone Pastor. Motete al Santísimo Sacramento a una voz o coro con acompañamiento de órgano (1913). Aprobado por la Comisión Diocesana de Madrid-Alcalá

6.2.4. Tantum Ergo. Motete al Santísimo a una voz con acompañamiento de órgano (1913). Tolerada por la Comisión Censora de Música Religiosa.

48. Sánchez de Andrés, L., "Compositoras españolas del siglo XIX: la lucha por espacios de libertad creativa desde el modelo de feminidad decimonónico", Álvarez, González, Gutiérrez, Marcos, (Eds.), Compositoras Españolas. La creación musical femenina desde la Edad Media hasta la actualidad. Madrid 2008.

49. Recuerda que "Ios fines de la música sagrada son dos: dar gloria a Dios y santificar a los fieles. Por otro lado, cuanto más disten las composiciones de la melodía gregoriana menos digna será de la Iglesia, admitiendo la música más moderna, pero sin estar compuesta en su forma externa imitando a las composiciones profanas". (Motu proprio de S.S. Pío X) 
6.2.5. Sacris Solemnis. Motete al Santísimo, para coro al unísono y a una voz sola con acompañamiento de órgano (1913). Tolerada por la Comisión Censora de Música Religiosa.

6.2.6. Sacris Solemnis. Himno al Santísimo para coro al unísono con acompañamiento de órgano (1913). Aprobado por la Comisión Diocesana de Madrid-Alcalá.

6.2.7. Oh Salutaris Hostia. Motete al Santísimo, para coro al unísono y a una voz sola con acompañamiento de órgano (1913). Tolerada por la Comisión Censora de Música Religiosa.

6.2.8. Salve Regina para cuatro voces con acompañamiento de piano u órgano (fecha desconocida).

\subsection{Música escénica}

Con el nacimiento del teatro por horas o secciones en el último tercio del siglo XIX, se produce un auge del teatro musical que dio lugar a una tipología de obras teatrales muy variadas. La brevedad obligada de las piezas propició el triunfo del género chico, basado en obras en un acto que no excedían de una hora de duración y que podían ir acompañadas de música, alternando el recitado con el canto.

El resultado fue, según Espín (2008): “...una anarquía de denominaciones de las piezas teatrales según se decantaran en ellas influencias, tendencias e intenciones más o menos acertadas de los dramaturgos" (p. 836) ${ }^{50}$. De esta forma, se produjo una denominación indiscriminada de muchas de las piezas, sin ninguna diferenciación formal o de contenido entre dichas obras.

Siguiendo a Espín (2008), el análisis en estas obras da lugar a una serie de subgéneros dramáticos dentro del género chico como sainete-pasillo, revista, juguete cómico, zarzuela parodia, comedia y opereta que suelen ir acompañados de otros adjetivos como cómico, lírico, cómico-lírico, cómico-dramático, etc. Estos adjetivos pretenden aclarar las características de la obra. Por ejemplo, el adjetivo lírico afirma que existe música en dicha obra.

Debemos diferenciar también que, debido a otra serie de denominaciones costumbristas, la zarzuela no siempre se refiere al subgénero de zarzuela breve del teatro por horas, sino simplemente al hecho de que una pieza lleve música ${ }^{51}$.

50. Espín, M. P., “Tipología de las formas teatrales breves dentro del género chico. El problema de las denominaciones", Huerta Calvo (Dir.), Historia del teatro breve en España (III). Madrid 2008, pp. 835-851.

51. Espín, M. P., "Tipología de las formas teatrales breves ...", pp. 835-851. 
Relacionado con la mujer compositora, existe paralelamente otro tipo de representación dramática breve como es el teatro infantil. Existe una especial deriva por parte de compositoras y escritoras teatrales de preguerra, hacia el teatro destinado a centros escolares.

Tal y como afirma Nieva (1993) en su libro Autoras Dramáticas Españolas entre 1918 y 1936 :

La tradicional vinculación de la mujer con la carrera pedagógica, así como la clásica definición de la "esencia" femenina en relación con el matrimonio y la maternidad explican en buena medida la general aceptación de las producciones para el teatro de niños escritas por mujeres, frente al frecuente rechazo con que se las recibía en otras parcelas de la creación dramática. (p. 249) ${ }^{52}$

Como ya explicamos anteriormente, representantes del teatro escolar didáctico y moralizante fueron Pilar Contreras de Rodríguez y Carolina de Soto y Corro, habitual colaboradora de la primera. Se trata fundamentalmente de un teatro pensado para ser representado en colegios femeninos de religiosas, aunque también para la representación escolar con fines benéficos y fiestas de caridad.

De tradición decimonónica, este tipo de producción teatral se escribe casi siempre en verso y con muy pocos recursos para su puesta en escena, exceptuando el vestuario de los estudiantes pensado para el lucimiento ante sus familias.

Entre las obras escénicas recopiladas de Remedios de Selva encontramos las siguientes:

6.3.1. Lo que el dinero no compra. Zarzuela en un acto y tres cuadros. Se estrena el 12 de mayo de 1909 en el teatro Nuevo de Alicante. El libreto es de José de Campos y la música de Remedios de Selva, se conserva un manuscrito donde se puede leer "Parte de apuntar". Ejemplar ms., 1910.

6.3.2. Una jira. Sainete en un acto y dos cuadros. (Para niños solos). Letra y Música de Remedios de Selva. Madrid, Unión Musical Española, (1932), reducción para piano.

6.3.3. El tesoro de Riquín. Zarzuela infantil en un acto. Libreto de Luis de León y música de Remedios de Selva. Faustino Fuentes, (1922)

6.3.4. La tranquilidad, pensión para señoras (1926). Sainete lírico en un acto. Letra y música de Remedios de Selva. Madrid, Faustino Fuentes.

6.3.5. Niní y Beatriz (primera edición en 1932). Zarzuela en un acto y tres cuadros. (para niñas solas). Libreto de José de Campos y música de Remedios de Selva. Madrid, Unión Española, reducción para piano.

52. Nieva, P., Autoras dramáticas españolas entre 1918 y 1936. Madrid 1993. 
6.3.6. La Cueva de San Antón. Zarzuela cómico-dramática en un acto y en verso. (Para niños). De esta zarzuela en cuya portada podemos leer "Teatro para niños", sólo disponemos del libreto, escrito por José Zahonero, donde indica que la música es de Remedios de Selva y se alternan partes habladas y cantadas. La primera edición es de 1916.

\subsection{Música de salón}

Las partituras de este repertorio no han sido encontradas por el momento. Sabemos de su existencia y, que fueron interpretadas en conciertos, por la prensa de la época.

Se trata en su mayoría de formas musicales de inspiración española que se pusieron de moda a principios del siglo XX. De su incursión en el mundo político y militar encontramos Marcha triunfal al general Marina (1910) mostrando un interés de carácter patriótico por los hechos sucedidos en la Guerra de Melilla.

Las composiciones de música de salón recopilados son las siguientes:

6.4.1. Gurugú. Pasodoble (1910)

6.4.2. Marcha triunfal al general Marina (1910)

6.4.3. Lo que son tus besos. Canción, de Prado, Prats y Remedios de Selva (1925)

6.4.4. Serranilla. Canción, letra de Jerónimo Gómez Rodríguez (1913)

6.4.5. Los músicos de la Arcadia. Cuarteto descriptivo para piano, violín, viola y violonchelo (1913), inspirado en una leyenda.

\section{Conclusiones}

Se ha podido constatar que Remedios de Selva y Torre ingresó en el Conservatorio de Madrid con la intención de recibir una formación que le proporcionase el desarrollo de una carrera profesional en el mundo de la música.

Ante la falta de estudios que den luz sobre el alcance de la actividad musical de las mujeres, esta investigación ha intentado recuperar del olvido a dicha compositora, además de recopilar y clasificar su obra. Futuras investigaciones ampliarán, no sólo el conocimiento sobre la vida y la obra de Remedios de Selva sino también un análisis exhaustivo de su creación musical.

\section{Bibliografía}

BUENAVENTURA SELVA, Narciso: Comentarios al código penal reformado y planteado provisionalmente por Ley de 3 de Junio de 1870, Madrid, Imprenta Española, 1870. 
DE SELVA, Remedios: "Música Italiana", Los ciegos (Madrid), 10 (noviembre de 1917), pp. 8-9.

DE SELVA, Remedios: "Música Profana", Los ciegos (Madrid), 10 (noviembre de 1917), p. 9.

DE SELVA, Remedios: "Música Italiana (conclusión)", Los ciegos (Madrid), 11 (diciembre de 1917), pp. 8-10.

DE SELVA, Remedios: "Ciegos Ilustres: Fray Pablo de Nasarre", Los ciegos (Madrid), 44 (enero de 1921), pp. 5-7.

DE SELVA, Remedios: "Carlos Terraza de Vesga", Los ciegos (Madrid), 46 (marzo de 1921), pp. 5-7.

DE SELVA, Remedios: "La ciega guía de las catacumbas de Roma", Los ciegos (Madrid), 47 (abril de 1921), pp. 6-7.

DE SELVA, Remedios: "Fray Pedro de Ureña", Los ciegos (Madrid), 48 (mayo de 1921), p. 5.

DE SELVA, Remedios: "El pescador de Calamar", Los ciegos (Madrid), 49 (junio de 1921), pp. 12-13.

ENCINA CORTIZO, María: "La formación de Chapí en el Conservatorio de Madrid: el magisterio de Arrieta", en Víctor SÁNCHEZ SÁNCHEZ, Javier SUÁREZ PAJARES y Vicente GALBIS LÓPEZ (eds.): Ruperto Chapí. Nuevas perspectivas. Vol. 2, Valencia, Institut Valencià de la Música, 2012, pp. 81-97.

ESPÍN TEMPLADO, María del Pilar: "Tipología de las formas teatrales breves dentro del género chico. El problema de las denominaciones", en Javier HUERTA CALVO (coord.): Historia del teatro breve en España (III), Madrid, Iberoamericana, Vervuert, 2008, pp. 835-852.

HERNÁNDEZ ROMERO, Nieves: “Educación musical y proyección laboral de las mujeres en el siglo XIX: el Conservatorio de Música de Madrid", Trans: Revista Transcultural de Música, 15 (2011), s.n.

HERNÁNDEZ ROMERO, Nieves: Formación y profesionalización musical de las mujeres en el siglo XIX: El Conservatorio de Madrid, Alcalá de Henares, Ayuntamiento de Alcalá de Henares, 2019.

MONTIJANO RUIZ, Juan José: Historia del Teatro olvidado: la Revista (18642009), Tesis doctoral, Granada, Universidad de Granada, 2009.

NAVARRO SALES, José Manuel: Diccionario de la lírica en Alicante. Casi dos siglos de zarzuela y ópera, Alicante, Instituto Alicantino de Cultura Juan GilAlbert, 2007.

NIEVA DE LA PAZ, Pilar: Autoras dramáticas españolas entre 1918 y 1936, Madrid, Consejo Superior de Investigaciones Científicas, CSIC, 1993.

PALACIOS NIETO, María: "Música y género en la España de principios del siglo XX (desde 1900 hasta la posguerra y el exilio)", en Antonio ÁLVAREZ CAÑIBANO (coord.): Compositoras Españolas. La creación musical femenina 
desde la Edad Media hasta la actualidad, Madrid, Centro de Documentación de Música y Danza, INAEM, 2008, pp. 75-90.

s.a.: Anuario del Comercio de la Industria de la Magistratura y de la Administración de España y sus Colonias. Toledo (part. Jud. Talavera de la Reina) 1909.

s.a.: Anuario del Comercio de la Industria de la Magistratura y de la Administración de España y sus Colonias. Toledo (part. Jud. Talavera de la Reina) 1911.

SÁNCHEZ DE ANDRÉS, Leticia: "Compositoras españolas del siglo XIX: la lucha por espacios de libertad creativa desde el modelo de feminidad decimonónico", en Antonio ÁlVAREZ CAÑIBANO (coord.): Compositoras Españolas. La creación musical femenina desde la Edad Media hasta la actualidad, Madrid, Centro de Documentación de Música y Danza, INAEM, 2008, pp. 55-74.

SARGET ROS, María Ángeles: "Rol modélico del conservatorio de Madrid II (1868-1901)", Ensayos: Revista de la Facultad de Educación de Albacete, 17 (2002), pp. 149- 176.

TOLOSA, Manuel de A.: "Escuela de Música y Declamación", Bellas Artes (Madrid), 22 de noviembre de 1898, p. 5.

\subsection{Artículos de prensa}

Boletín Oficial de la Provincia de Madrid (Madrid)

- "Providencias Judiciales", Boletín Oficial de la Provincia de Madrid (Madrid), 15 de diciembre de 1908, p. 4.

Correspondencia de España (Madrid)

- "El teatro en provincias", Correspondencia de España (Madrid), 12 de mayo de 1909, p. 4.

Diario Universal (Madrid)

- "Noticias", Diario Universal (Madrid), 23 de noviembre de 1918, p. 2.

- "Publicaciones", Diario Universal (Madrid), 15 de marzo de 1922, p. 3.

Gaceta de Madrid (Madrid)

- "Ministerio de Gracia y Justicia", Gaceta de Madrid (Madrid), 25 de mayo de 1918, p. 512.

Gaceta de Instrucción Pública y Bellas Artes (Madrid)

- "Administración Central", Gaceta de Instrucción Pública y Bellas Artes (Madrid), 14 de febrero de 1917, p. 109.

Gran Vía de Madrid (La) (Madrid)

- "Escuela Nacional de Música y Declamación", La Gran Vía de Madrid (Madrid), 127 (14 de diciembre de 1895), p. 10. 
- "Escuela Nacional de Música y Declamación", La Gran Vía de Madrid (Madrid), 127 (14 de diciembre de 1895), p. 11.

- "Escuela Nacional de Música y Declamación", La Gran Vía de Madrid (Madrid), 127 (14 de diciembre de 1895), p. 13.

Heraldo de Madrid (Madrid)

- "Espectáculos", Heraldo de Madrid (Madrid), 17 de mayo de 1909, p. 4.

- "Exposición Nacional de Trabajos de Ciegos", Heraldo de Madrid (Madrid), 17 de junio de 1917, p. 2.

- "Sucesos de Madrid", Heraldo de Madrid (Madrid), 2 de septiembre de 2011, p. 2.

Imparcial (EI) (Madrid)

- "Radiotelefonía", El Imparcial (Madrid), 17 de marzo de 1925, p. 7.

Libertad (La) (Madrid)

- "Radiotelefonía", La Libertad (Madrid), 17 de marzo de 1925, p. 2.

- "Radiotelefonía", La Libertad (Madrid), 18 de marzo de 1925, p. 2.

Liberal (EI) (Madrid)

- "Sucesos", El Liberal (Madrid), 2 de septiembre de 2011, p. 5.

Mañana (La) (Madrid)

- "Noticias Generales", La Mañana (Madrid), 12 de agosto de 1917, p. 5.

- "Sucesos de Madrid", La Mañana (Madrid), 2 de septiembre de 2011, p. 2.

- "Vida Palatina", La Mañana (Madrid), 5 de junio de 2018, p. 3.

Mensajero Leonés (León)

- "Noticias", Mensajero Leonés (León), 12 de septiembre de 1905, p. 2.

- "Noticias", Mensajero Leonés (León), 22 de noviembre de 1905, p. 2. 